\title{
ACRL/CNI select Case Western for virtual user education collection
}

ACRL and the Coalition for Networked Information (CNI) selected Case Western Reserve University (CWRU) as the site to develop a virtual collection of Internet user education and training materials. The purpose of this project is to identify exemplary user education and training materials related to the Internet and networked information resources, especially those materials which integrate print and electronic resources and teach evaluation of networked resources.

CWRU agreed to develop a mechanism for bringing those items together in a distributed environment, e.g., via a Web page, and to encourage authors of exemplary materials to mount them on the Internet on a server or to provide that service for them as a repository of last resort.

4 This announcement is the culmination of a process begun in 1993 as part of ACRL president-elect Tom Kirk's presidential theme of networking. In June 1993, the Emerging Technologies in Instruction Committee, on behalf of the Bibliographic Instruction Section (now the Instruction Section), began work on a project to foster effective strategies for instructing users in the networked information environment. In addition, CNI expressed specific interest in finding ways to explore use of the network itself to provide both instruction on the actual use of the Internet and other curricula, and measurement and evaluation of Internet resources and services.

In June 1994, the Committee on Emerging Technologies released "User Education for the Internet: Report and Recommendations," which included a key recommendation that the Instruction Section (IS) establish an ongoing mechanism to identify excellent instructional programs and materials for teaching in the networked environment, and work within ACRL and with CNI to maintain a suitable elec-

9958; or write: ACRL Order Fulfillment, $155 \mathrm{~N}$. Wacker Dr., Chicago, IL 60606.

\section{Log-on@thelibraryday}

ALA encourages all libraries to join logon@thelibraryday, Tuesday, April 16, 1996, dur- tronic resource of such information.

In September 1995, at the request of IS, CNI posted a "Call for Participation" asking interested institutions to submit a proposal for developing a virtual collection of Internet user education and training materials.

The call received eight excellent proposals from institutions with strong networking credentials. A review committee of members of the Emerging Technologies Committee and CNI selected Case Western Reserve after a lengthy review of the proposals.

Keith Morgan, chair of the Emerging Technologies Committee, said, "the committee is excited by the prospect of developing this collection in partnership with CWRU. A central site showcasing excellent models of Internet instruction can be a valuable resource for all librarians involved with teaching the Internet."

Ray Metz, interim director of the CWRU Library and director, Library Information Technologies, echoed this reaction: "We are very excited about hosting the CNI/ACRL site. Educating our users about digital information is a major component of our vision for our library. We are excited about the opportunity to begin working with the next generation of user education materials which we anticipate will be more interactive and multimedia."

Announcement of URLs and a request for submission of materials will be made soon. Further information is available on the Emerging Technologies Web Page at either http:// www2.colgate.edu/instruction/ or http:// www.lib.ncsu.edu/staff/kamorgan/etech. html.

For further information contact: Keith Morgan, North Carolina State University, e-mail: Keith_Morgan ncsu.edu; or Joan K. Lippincott, CNI, e-mail: joan@cni.org; or Tom Klingler, CWRU, e-mail: tek5@po.cwru.edu.

ing National Library Week celebrations. Demonstrations will introduce the public to the information superhighway and spotlight the role of libraries in linking students and the public with the new information technology. A "tour guide," including the White House, Congress, 